.

\title{
REVIEW OF PUBLIC PRIVATE PARTNERSHIP IN HEALTH CARE IN HONG KONG
}

\author{
Cynthia Lau, Ben Yuk Fai Fong \\ School of Professional Education and Executive Development, College of Professional and Continuing Education, The Hong Kong \\ Polytechnic University
}

Correspondence: cynthialau1227@gmail.com

\begin{abstract}
Public Private Partnership Programme is a cooperation between different healthcare professionals in both public and private sectors in Hong Kong. Over the decades, many programmes have been developed which cover various diseases, including chronic conditions and surgery for cataracts, as well as vaccinations. However, these programmes are not successful because of the unsatisfactory service charges in the private sector, overlapped aims and resources and wrong estimation of needs. To become successful, programmes reform is required by rearranging resources, annual reviews, more financial support and extending the coverage of diseases. Promotions of programmes are beneficial to all stakeholders. Overall, better coordination between both sectors is the essential factor which can lead the programme to success and maintain a better health care system in Hong Kong.
\end{abstract}

\section{KEYWORDS}

Public Private Partnership, Health Care System, Coordination, Reform, Hong Kong.

\section{HEALTH CARE SYSTEM IN HONG KONG}

There are elements of both the public and private sector involved in the delivery services in the Hong Kong Special Administrative Region (SAR)

\subsection{PUBLIC SECTOR}

The Food and Health Bureau is responsible for making policy decisions and allocating resources to maintain the operations of public services of the health care system in Hong Kong. Two organisations are responsible to manage the public health care facilities. The Department of Health of the government manages services related to public health and primary care, supported by the Centre for Health Protection and other respective units, including infection control, social hygiene and prevention of communicable diseases and non-communicable diseases. The Department of Health also provides health education, assessment of children and supervision of elderly homes and family health. [1] The Hospital Authority (HA), a statutory body, manages all of the 43 public hospitals of a total of 28,000 beds, 49 specialist Out-patient clinics (SOPCs), and 73 general out-patient clinics (GOPCs). With a staff of 79,000, the HA provides inpatient and outpatient services, as well as community outreach services for 
patients who are disabled or have difficulty accessing the hospital for follow up. Public hospitals are grouped into seven clusters based on the geographic locations to make it easy for people to continue the treatment within or near their living area. [2]

\subsection{PRIVATE SECTOR}

In the private sector, there are 12 private hospitals and many private clinics in both general practice and clinical specialties. Elderly homes, medical laboratories, community pharmacies and diagnostic imaging centres are also part of the services in the private sector. They are self-financed and give alternative choices for people according to their ability to pay. [3] In the dual-track health care system in Hong Kong, the private sector has been expanding because in the past two decades more patients are coming from Mainland China and the demand by local people also keeps increasing. Patients can choose the doctors and the waiting time is shorter. They can also participate in decisions about the treatment such as the need of hospitalization and the mode of surgery. [4] There are insurance schemes to encourage people to use private health care services. In addition, the government also offer health care vouchers to the elderly for use in the private sector. The pressure on the public sector is expected to be reduced and people can receive better care services. The government has been promoting cross-sector cooperation between the two sectors for over 20 years, known as the Public Private Partnership (PPP).

\section{PUBLIC PRIVATE PARTNERSHIP}

\subsection{DEVELOPMENT OF PUBLIC PRIVATE PARTNERSHIP IN HONG KONG}

Public Private Partnership (PPP) is an arrangement of cooperative institutions operating between the private and public sectors. To provide public projects and services, private organisations use their complementary techniques with different levels of responsibilities, including financial commitment, expertise and involvement in the projects in the areas of transport, like the tunnels across the harbour, and housing development, the home-ownership scheme. $[5,6]$ The government announced a series of pilot measures to promote public private partnership in health care services in the 2008-2009 policy address. The private sector is subsidised to provide preventive care to the public. Private hospital and primary care services are purchased, and some medical centres are being set up, including in the specialties of neuroscience and paediatrics. [7] Over the years, both the Department of Health and HA have implemented a number of programmes of public private partnership through the Electronic Health Record Sharing System. Private providers can access past medical history of patients when they manage public patients.

There are now 10 public private partnership programmes launched by the Department of Health and the HA, including PPP in general outpatient clinic; a project on enhancing radiological investigation services through collaboration with the private sector; the cataract surgeries program; the haemodialysis PPP; the patient empowerment program; the provision of infirmary service through PPP; colon assessment PPP; glaucoma PPP; colorectal cancer screening pilot program; Elderly Healthcare Voucher Scheme and the Vaccination Subsidy Scheme. They target patients who are suffering from endstage kidney failure, chronic diseases, cancers and eye diseases including glaucoma and cataract. Some programs aim at prevention and early detection such as screening of colorectal cancer, and some provide infirmary care and healthcare services to the elderly. [8, 9, 10]

\subsection{ELEMENTS OF SUCCESS IN PUBLIC PRIVATE PARTNERSHIPS}

To make public private partnership successful, there are five attributes involved. [11] These are addressing the needs of the health system, being sensitive to the context, recognising the patients as a key party, problem solving, sharing the risks.

The first attribute is to address the needs of the health care system. The government should know the current needs and what may be required in the future so that they can focus and respond to the system. Once they have prioritized the needs, they find stakeholders to support and join the plans. The planned programme should aim at the right group and achieve the goals.

The second attribute is being sensitive to the context. The different factors in Hong Kong should be considered for all the stages of development. For example, the market situation and share of health care, capability, capacity, transparency, etc. The challenges should be assessed, and resolutions planned. An accurate view on how to work within a set of circumstances should be in place to lower the risks. The third attribute is to recognize patients as a key party. Patients' wants and needs are important. Better 
outcomes will be derived from incentives and in-depth understanding of the collaboration in a patient-centred approach. For example, there is a small number of patients who have high usage of healthcare service. If the partnership programme can support them with early intervention, the government can reduce some costs and make better use of the resources.

The fourth attribute is problem-solving. During the promotion of the programmes, there may be many problems. New solutions and emerging technologies can help to minimize and solve the consequences. The last attribute is to share the risks. Both the public and private sectors have the responsibilities in the process of risk management, which cannot be transferred to the others. Therefore, a successful public private partnership programme should consider and assess all factors related to the capabilities and structure of participating entities, achieving a synergistic and complementary leverage [11].

To give particular emphasis to the Hong Kong SAR contexts similar health systems in other national contexts are reviewed.

\section{EXAMPLES OF PUBLIC PRIVATE PARTNERSHIP IN SINGAPORE AND UNITED KINGDOM}

Health care delivery in Hong Kong is similar to the systems in Singapore and the United Kingdom (UK) arising from historical reasons. PPP in both countries are good illustration of such programs in the health care system because of their longer history and success.

\subsection{SINGAPORE}

The healthcare system in Singapore is managed by The Ministry of Health. The public sector provides $72 \%$ of hospital beds while the private sector provides the remaining $28 \%$.
[12] $80 \%$ of patients choose outpatient services in the private sector but they use inpatient services in the public sector. [13]

Public private partnership of Singapore is concerned about health services provision and health care financing. There are four combinations of health care provision as shown in Figure 1. [14] Health care financing comes from government subsidy and co-payment by citizens. Although citizens should pay when using healthcare services in either public or private sector, and the charges can be covered by their private insurance, self-insurance, social insurance or taxes. [13]

In 1984, a health financing system, known as "3M" was introduced to promote medical saving. There are 3 schemes in the system. "Medisave" is a compulsory individual medical savings account. The fund comes from deductions from employee payroll. It can be used in hospitalization, outpatient services and surgery. "Medishield" is a low-cost insurance plan on a voluntary basis. It protects all permanent residents and Singapore citizens, including those of old age, those with pre-existing medical conditions and, those who suffer from financial losses during sickness. It also covers disastrous illnesses which are not covered by "Medisave". "Eldershield" is developed under this scheme and covers long-term care for serious disabilities. Besides, the whole programme of "Medishield" provides free upgrade for amenities from private insurance providers. The "Medifund" is governmentfunded scheme for the poor people. It is operated by voluntary welfare organizations and helps to cover the charges which patients cannot afford. The interest derived from the capital set up in 1993 is distributed to the non-profit and public hospitals. It also sets up the "ElderCare" fund to assist the elderly and "Medifund Silver" to support the elderly who cannot pay the public hospitals under "Medifund". [15] 


\section{Provision}

\begin{tabular}{|c|l|l|}
\multicolumn{1}{c}{} & \multicolumn{1}{c}{ Public } & \multicolumn{1}{c}{ Private } \\
\cline { 2 - 3 } Fublic & $\begin{array}{l}\text { Publicly financed } \\
\text { Publicly provided }\end{array}$ & $\begin{array}{l}\text { Publicly financed } \\
\text { Privately provided }\end{array}$ \\
\cline { 2 - 3 } Private & $\begin{array}{l}\text { Privately financed } \\
\text { Publicly provided }\end{array}$ & $\begin{array}{l}\text { Privately financed } \\
\text { Privately provided }\end{array}$ \\
\cline { 2 - 3 } & &
\end{tabular}

Public-private partnership in Singapore is successful partly because the government promotes self-responsibility of health among the people. This can decrease the overutilisation, check abuses of health care services and prevent over reliance on insurance and welfare. The basic health care services can also be maintained with high quality and affordability.

\subsection{UNITED KINGDOM}

The health care system in United Kingdom is managed by the Department of Health of the government, which is responsible for the National Health Service (NHS). The NHS works with values and principles in which, like Singapore, all citizens have their own responsibilities to help to make sure that the services can run effectively and fairly. [16]

The NHS has established over 130 PPP projects in the past 20 years and they cover acute, community, mental and primary health services. [17] They are part of New Public Management (NPM) introduced in the 1980s and 1990s. As the government would like to enhance the service management and delivery in the public sector, they have cooperated with the private sector by employing the market-type mechanisms and neoliberalism. This approach can also breakdown the financial challenges for the government. [16]

The United Kingdom adopts a socialized medicine model which provides healthcare services by the government and funded by taxation. They control the organization of health service and finance in a capitalist economy and pay the healthcare providers directly. They own most of the equipment and facilities and allow some private care at patients' own expenses. They also pay and recruit healthcare professionals and operate the hospitals. These expenditures are funded by the NHS. [18]

The success of PPP programmes in UK is due to the welldeveloped rules and regulations as well as the management of the health care system by the government. The NHS keeps modifying the rules and regulations and improve the service of the programmes to provide effective services to the public. The NHS has the power to monitor the performance of the private sector and offer reasonable charges which people can afford. Such structure and arrangement are beneficial to the NHS, private sector and citizens by providing the best health care service. [19]

The use of PPP in Singapore and the UK provide lessons for the approach in Hong Kong that are know reviewed.

\section{REVIEW OF LOCAL HONG KONG PROGRAMMES UNDER PUBLIC PRIVATE PARTNERSHIP}

According to the HK Legislative Council's paper in 2015, there were near 100,000 patients participating in different programmes, mostly in the Patient Empowerment Programme which provided more knowledge and selfcare prevention of chronic diseases. [20] General outpatient clinic PPP Programme also had $90 \%$ of enrolled patients participating in it, which expanded the service to all 18 districts in 2018. [21]

The programme is not effective because it aims at patients with chronic diseases, but integrated care is not being 
provided to them, especially for those who suffer from more than one type of chronic diseases. Although it can decrease the working pressure in the public sector, patients still go back to the accident and emergency departments of public hospitals for consultations during the non-working hours of private clinics.

Another concern is the cost charged by participating private doctors for non-regular items not covered by the programme, including medications. This practice has affected the enrolment in the PPP programme because patients need to pay the extra co-payment themselves. Service quality management is also a major issue of concern since private doctors are independent contractors although they are bound by the code of professional conduct. In order to provide better service to patients, the government should collect opinions from the patients on the satisfaction of services, the health conditions and the habit of consultation. Such data may be useful in planning for the further directions of the PPP programs. [22]

\section{RECOMMENDATIONS}

The authors make the following recommendations.

\subsection{PROGRAMME REFORM}

Programmes of similar nature can be re-developed or combined to avoid duplication or waste of resources, so that public money is spent more efficiently and effectively to meet other needs of the community. Simplification of procedures for both the users and health services providers is also important in the operations of PPP programmes. Health technology can be employed to streamline registration and consultations.

\subsection{IMPORTANCE OF ANNUAL REVIEW}

Annual review of all PPP programs is recommended. Feedback and opinion of both the patients and providers are important in the planning, implementation and delivery of appropriate and quality services, more so since the expectations and requirements of health services keep changing over time. The government, private health sector, and non-government organizations, which are also potential "private" service providers, should be innovative and sensitive to the context of the services and the needs of patients, and expand the programmes to cover more services, particularly when there is a surge of demand in the public sector, like during the annual seasonal influenza.

\subsection{ENHANCEMENT OF PUBLICITY}

Enhancement of publicity with strategic activities in social marketing is instrumental in promoting the PPP programs. The Department of Health and HA can do more by creating media such as posters, leaflets and videos targeted at the patients and service providers. The Department can draw the attention of the public to start considering the alternative choices of health service in the private sector, in meeting their health needs for the health conditions they have.

\subsection{FINANCIAL INCENTIVES}

Financial incentives to private health practitioners are essential considerations in order to encourage them to participate and stay in the programs. Private providers expect reasonable returns. Feasible and practical charges schedules help to recruit more participating providers from the private sector. PPP programs cannot be sustained if there are not enough panel service providers, particularly when the PPP is run on a voluntary basis.

\subsection{PROFESSIONAL TRAINING TO PUBLIC AND PRIVATE SECTORS}

There is inconsistency in the standards and quality of services by the private sector. Thus, professional organisations of healthcare disciplines, the HA, private sector and tertiary institutions can organise induction briefs and training to standardize the common practices and promote service quality. In addition, short courses, discussion forums and technical exchange workshops on common issues of public health in the community such as non-communicable diseases, outbreak management, emergencies, health promotion, can be conducted. Such programmes can enhance the skills and knowledge of the providers and keep them abreast of the latest professional development.

\subsection{BETTER COORDINATION OF PUBLIC AND PRIVATE SECTORS}

Both the public and private sectors should have better coordination to attain smooth operations of PPP programs. Currently, service providers can access patients' medical history from e-health records through the eHR sharing eHealth system (eHRSS), provided that both service providers

Review of public private partnership in health care in Hong Kong 5

Asia Pacific Journal of Health Management 2021; 16(1):i637. doi: 10.24083/apjhm.v16il.637 
and patients have already registered in the eHRSS. Service providers can then keep track of the situation of patients even when they change to other providers. In time of unexpected or unusual public events, like natural disasters and the COVID-19 outbreak, providers in the private sector can help in the management of selected patients, who are in stable conditions. The PPP will help to maximise the utilisation and effectiveness of social resources.

\section{CONCLUSION}

Public Private Partnership programmes are the cooperation between the public and private sectors in the health care system. Throughout these decades, the government in some countries, like Singapore and UK, have developed different programs but some of them are limited by resources. To improve the services, it is the time to review and reform these programmes by adopting the five attributes: (i) to address the needs of the health care system; (ii) to be sensitive to the context of the services; (iii) to recognize patients as a key party; (iv) to attend to problem-solving; and $(v)$ to share the risks between the two sectors. Furthermore, there should be appropriate resources reallocation, annual reviews, enhanced promotion and social marketing, increase in financial support, and coverage of more common conditions. Most importantly, both sectors should work closely and have better collaboration so that the programmes can benefit the community.

\section{References}

1. Department of Health. Main Service Areas. [Internet]. 2019. [cited 3 April 2020]. Available from: https://www.dh.gov.hk/english/main/main.html

2. Hospital Authority. Introduction. [Internet]. 2020. [cited 3 April 2020]. Available from:

https://www.ha.org.hk/visitor/ha_visitor_index.asp?Co ntent_ID $=10008 \&$ Lang $=E N G \&$ Dimension $=100 \&$ Parent_I $\mathrm{D}=10004 \&$ Ver $=H T M L$

3. Food and Health Bureau. Strategic Review on Healthcare Manpower Planning and Professional Development Report. [Internet]. 2017. [cited 3 April 2020]. Available from:

https://www.fhb.gov.hk/download/press and public ations/otherinfo/180500_sr/e_sr_final_report.pdf
4. Kong X, Yang Y, Gao J, Guan J, Liu Y, Wang R, et al. Overview of the Health Care System in Hong Kong and Its Referential Significance to Mainland China. Journal of the Chinese Medical Association. 2015; 78(10): 569-573.

5. Lee V. Public Private Partnership. [Internet]. 2005. [cited 3 April 2020]. Available from:

https://www.legco.gov.hk/yrO405/english/sec/library/0405rp03e.pdf

6. Hodge GA, Greve C. Public-Private Partnership: An International Performance Review. Public Administration Review. 2007; 67(3): 545-558.

7. The Government of Hong Kong Special Administration Region. 2008-09 Policy Address. [Internet]. 2008. [cited 3 April 2020]. Available from:

https://www.policyaddress.gov.hk/0809/eng/contact.html

8. Hospital Authority. Public Private Partnership. [Internet]. 2020. [cited 3 April 2020]. Available from: https://www3.ha.org.hk/ppp/homepage.aspx?lang= eng

9. Centre for Health Protection. Pilot Public-Private Partnership Programmes. [Internet]. 2019. [cited 7 November 2020]. Available from: https://www.chp.gov.hk/en/static/101334.html

10. Department of Health. Prevent Colorectal Cancer. [Internet]. 2020. [cited 3 April 2020]. Available from: https://www.colonscreen.gov.hk/mobile/en/index.ht $\underline{\mathrm{ml}}$

11. Quality Healthcare Medical Services Limited. The Power of Public-Private Partnerships: Steering Hong Kong Towards Comprehensive Primary Care. [Internet]. 2018. [cited 3 April 2020]. Available from: http://www.ahms.com/docs/Quality\%2OHealthCare T he\%20Power\%20of\%20PPP Report vF.pdf

12. Leong SW, Tan S, Hock CC, Tan G, Poh J. PublicPrivate Partnership in Healthcare Financing: Survey of East Asian Countries. In: Singapore Actuarial Society 3rd Health Insurance Conference 2012 [Internet]; 2012. [cited 25 June 2020]. Available from https://www.actuaries.org.sg/files/library/forum_prese ntation/2012/2012\%20HIC/S10.\%20PublicPvł\%20Healthcare\%20Financing\%20Partnership\%20Sur vey\%20-\%20Joyce\%20Poh.pdf 
13. Lim MK. Singapore Health Care: A Model of Prudent, Pragmatic, Public-Private Partnership. [Internet]. 2011. [cited 25 June 2020] Available from:

http://www.cuhk.edu.hk/hkiaps/PPT/LIM\%20Meng\%20 Kin 0304.pdf

14. Lim MK. Transforming Singapore Health Care: PublicPrivate Partnership. Annals of the Academy of Medicine Singapore. 2005;34(7): 461-467.

15. Lim MK. Singapore's Secret to Healthcare: PublicPrivate Collaboration for Cost-efficient, Hing-quality Healthcare. Handshake [Internet]. 2011 [cited 25 June 2020]; 3:68-72. Available from: https://library.pppknowledgelab.org/documents/4769 ldownload

16. Muza IR. The Role of Healthcare Public-Private Partnership and Health Systems Strengthening in United Kingdom. University of Bedfordshire. 2013 Jan. doi: 10.13140/RG.2.1.4799.4329

17. UK Trade \& Investment. Healthcare UK: Public Private Partnerships. [Internet]. 2013. [cited 7 July 2020].

Available from:

https://assets.publishing.service.gov.uk/government/u ploads/system/uploads/attachment data/file/266818 107_PPP_28.11.13.pdf

18. Edmonds M. 10 Health Care Systems Around the World. [Internet]. 2010. [cited 9 July 2020]. Available from: https://people.howstuffworks.com/10-healthcare-systems.htm

19. Cheung E, Chan APC, Kajewski S. Factors Contributing to Successful Public Private Partnership Projects: Comparing Hong Kong with Australia and the United Kingdom. Journal of Facilities Management. 2012;10(1):45-58.

20. Legislative Council. Proposed $\$ 10$ Billion Endowment Fund to the Hospital Authority for Public-Private Partnership Initiatives. [Internet]. 2015. [cited 4 April 2020]. Available from https://www.legco.gov.hk/yr1516/english/panels/hs/papers/hs20151116cb2-235-6$\underline{\text { e.pdf }}$

21. Hospital Authority. Annual Report 2018-2019. [Internet]. 2019. [cited 4 April 2020]. Available from:

https://www.legco.gov.hk/yr19-

20/chinese/counmtg/papers/cm20191218-sp077ec.pdf
22. Legislative Council. General Outpatient Clinic Publicprivate Partnership Programme. [Internet]. 2018. [cited 4 April 2020]. Available from:

https://www.legco.gov.hk/yr1718/english/panels/hs/papers/hs20180212cb2-827-6e.pdf 